\title{
A green method for the synthesis of Copper Nanoparticles using L-ascorbic acid
}

Asim Umer ${ }^{1}$, Shahid Naveed ${ }^{2}$, Naveed Ramzan ${ }^{3}$, Muhammad Shahid Rafique ${ }^{4}$, Muhammad Imran ${ }^{5}$

\author{
${ }^{1,2,3}$ Department of Chemical Engineering, University of Engineering and Technology, Lahore. \\ e-mail: asimumer@uet.edu.pk; drsnaveed335@gmail.com; ramzan50@ hotmail.com \\ ${ }^{4}$ Department of Physics, University of Engineering and Technology, Lahore. \\ e-mail: shahidrafiq@uet.edu.pk \\ ${ }^{5}$ College of Science and Technology, Model Town, Lahore. \\ e-mail: engr.imran955@gmail.com
}

\begin{abstract}
Chemical Reduction technique was employed to prepared highly stable and dispersed Copper nanoparticles using L-Ascorbic Acid (Vitamin C) as reducing as well as capping agent. In this technique, cupric chloride was used as precursor. The effects of different molar ratios of L-Ascorbic Acid on the concentration and size of copper nanoparticles were studied. The Copper nanoparticles were characterized by X-Ray Diffraction, Atomic Absorption Spectrometry, and Fourier Transform Infrared Spectrometry. The results show that with the increase in the molar ratio of L-ascorbic acid the concentration of Copper nanoparticles were also increased. The average particles size of copper nanoparticle was found in the range of 50-60 nm. The product was kept in ambient conditions for three month but no sedimentation or separation was observed. The use of ascorbic acid makes the process a non-toxic, cost effective and environmental friendly green method.
\end{abstract}

Keywords: Copper nanoparticles, ascorbic acid, copper salt, XRD, FTIR

\section{1 INTRODUCTION}

Copper nanoparticles $(\mathrm{Cu} \mathrm{NP})$ are very attractive due to their heat transfer properties such as high thermal conductivity. $\mathrm{Cu}$ NP also have high surface area to volume ratio, low production cost, antibacterial potency, catalytic activity, optical and magnetic properties as compared to precision metals such as gold, silver or palladium. The main difficulty lies in their preparation and preservation as they oxidized immediately when exposed in air. Scientists are using different inert media such as Argon, Nitrogen [1-3] to overcome this oxidation problem also using reducing, capping or protecting agents for the reduction of copper salt used. Some reducing and capping agents are very expensive and also have toxic effects.

Physical and chemical methods are two basic techniques for the synthesis of $\mathrm{Cu}$ NP. Pulsed laser ablation [4], vacuum vapor deposition [ 5] , pulsed wire discharge [ㅁ] and mechanical milling []] are physical techniques while Chemical reduction [] ], Microemulsion techniques [9], sonochemical reduction [10], Electrochemical [11], Microwave assisted [12], and hydrothermal [13] are chemical approaches for the synthesis of nanoparticles. Biological or biosynthesis [14] techniques are also considered as chemical methods. $\mathrm{Cu}$ NP has high thermal conductivity [15] and also the production cost is very low as compare to noble metals. $\mathrm{Cu}$ NP production using chemical reduction method gives good results but use of hazardous reducing and costly and protecting agent [16-22] makes the process toxic in some cases. To avoid the toxicity and to prepare $\mathrm{Cu}$ NP in green environment, we have used ascorbic acid in our chemical reduction process. Ascorbic acid works both as reducing and protecting agent, which makes the process economical, nontoxic and environment friendly [15]. The raw materials are the same as Jing Xiong [23]; however, the synthesis route and the equipments have been changed, which resulted in the size variation of NP in this work.

\section{2 EXPERIMENT AL}

\subsection{Chemicals used}


Copper (II) Chloride $\mathrm{CuCl}_{2} .2 \mathrm{H}_{2} \mathrm{O}$ (98 \% Pure) from Riedel-de Haen, Germany, L-Ascorbic Acid (99\% pure) from Merck, Germany, of analytical grade, were purchased and used without further chemical treatment and purification. L-Ascorbic acid was used as reducing as well as capping agent. De-ionized water was obtained from Institute of Environmental Engineering and Research, University of Engineering and Technology, Lahore, Punjab, Pakistan. (S.G 2000 Water Germany now owned by Siemens USA.)

\subsection{Synthesis of Copper nanoparticles}

A $500 \mathrm{~mL}$ of 0.01 molar Copper (II) Chloride $\left(\mathrm{CuCl}_{2} \cdot 2 \mathrm{H}_{2} \mathrm{O}\right)$ solution was prepared by dissolving that copper salt in de-ionized water. Solutions of $0.25 \mathrm{M}, 0.5 \mathrm{M}, 0.75 \mathrm{M}$ and $1.0 \mathrm{M} \mathrm{L}$-Ascorbic Acid were prepared in deionized water. Four air tight flasks, each having $50 \mathrm{~mL}$ of $\mathrm{CuCl}_{2} \cdot 2 \mathrm{H}_{2} \mathrm{O}$ solution were heated continuously at $90^{\circ} \mathrm{C}$ in water bath shaker (electrical/mechanical heated).

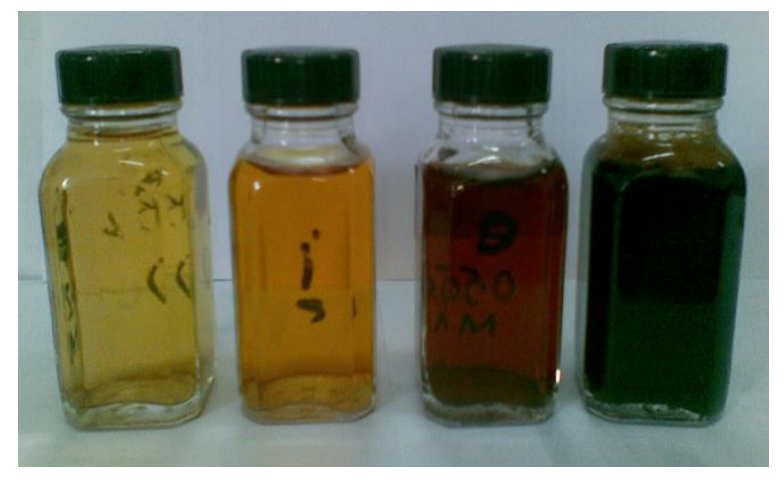

Figure 1: Synthesis steps of $\mathrm{Cu}$ NP.

The solution of $0.25 \mathrm{M}, 0.5 \mathrm{M}, 0.75 \mathrm{M}$ and $1.0 \mathrm{M} \mathrm{L}$-Ascorbic Acid were added drop wise to each flask respectively. The heating and mixing continued till the color changed from no color to yellow, orange, brown and finally dark brown-black as shown in Figure 1. The whole process was completed within 17 hours. The product was kept for 12 weeks, no sedimentation or dispersion was observed with no magnification.

\subsection{Characterization}

The concentration of synthesized $\mathrm{Cu}$ NP was evaluated using Atomic Absorption Spectrometer (AA6800, Shimadzu, Japan). FT-IR spectrum were accomplished and recorded with Fourier-Transform infrared spectrophotometer (Bruker, Alpha ATR) between 4000 and $375 \mathrm{~cm}^{-1}$, with resolution of $4 \mathrm{~cm}^{-1}$. The morphology and size of produced nanoparticles were characterized by X-Ray Diffraction (XRD), PANalytical, X'Pert PRO XRD system.

\section{3 RESULTS AND DISCUSSION}

\subsection{Atomic Absorption Spectrometry}

A sample of $0.1 \mathrm{~mL}$ prepared Cu NPs solution from each flask was obtained and diluted to $100 \mathrm{~mL}$ by adding de-ionized water. Standard copper solutions $(0.5 \mathrm{ppm}, 1.0 \mathrm{ppm}, 2.0 \mathrm{ppm}$ and $5.0 \mathrm{ppm})$ were prepared as reference. By adjusting the wavelength of Atomic Absorption Spectrometer at $324 \mathrm{~nm}$, the samples were analyzed.

The concentration-Absorption graph confirms the presence of copper and the Beer-Lambert's laws (the proportional relationship between the concentration and absorption) proving that the concentration of $\mathrm{Cu}$ NPs increased in different prepared samples. It also revealed that the concentration of $\mathrm{Cu}$ NPs increased rapidly when the concentration of L-Ascorbic acid was increased gradually whereas the concentration of copper chloride was kept constant as shown in Figure 2.

Figure 3 shows the relationship between $\mathrm{Cu}$ NP and absorption and it is clear that the absorption increases as the nanoparticles concentration increases. 


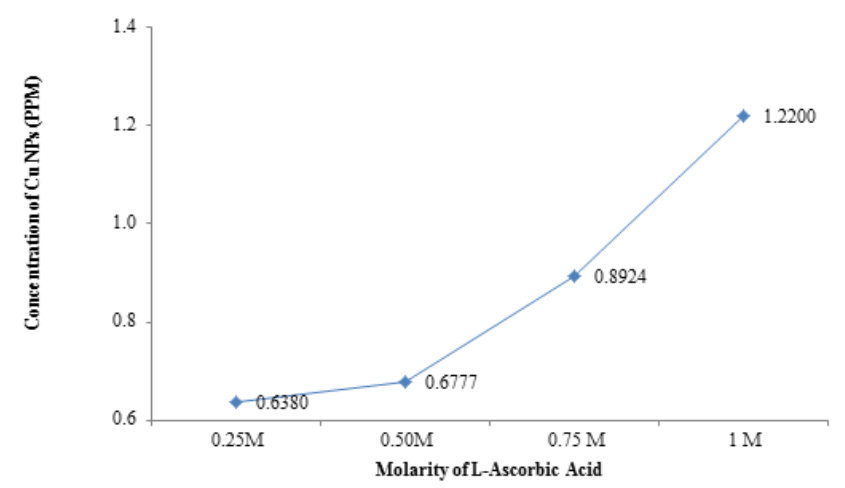

Figure 2: Effect of the L-Ascorbic Acid concentration on the synthesis of Cu NPs.

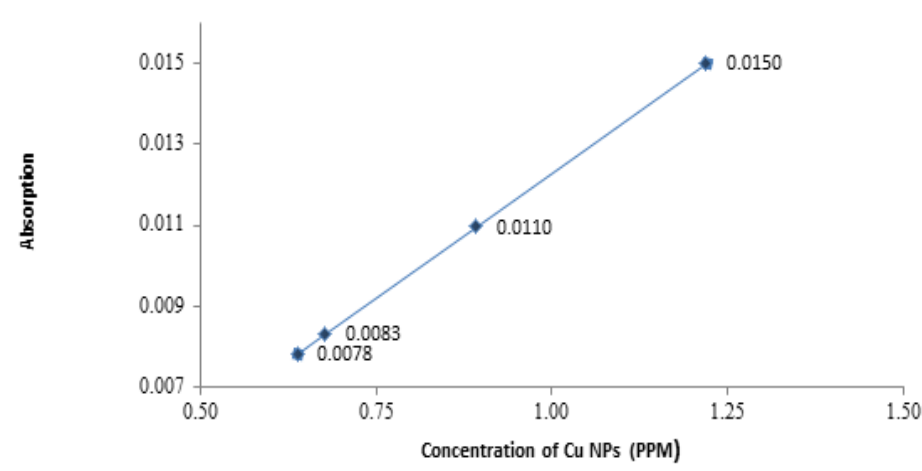

Figure 3: Relation of $\mathrm{Cu}$ NPs concentration and Absorption.

\subsection{Fourier Transform-Infra Red (FT-IR) Spectrometry}

The interaction of L-Ascorbic Acid and $\mathrm{Cu}$ nanoparticles and the mixture composition changes were studied by FT-IR spectrometry. The IR spectra of pure L-Ascorbic Acid is represented in Figure 4. The spectrum of pure L-Ascorbic Acid revealed that the stretching vibration of $\mathrm{C}-\mathrm{C}$ double bond and the peak of enolhydroxyl were observed at $1674 \mathrm{~cm}^{-1}$ and $1322 \mathrm{~cm}^{-1}$, respectively. These were replaced after the reaction with new peaks $3311.88 \mathrm{~cm}^{-1}, 1635.01 \mathrm{~cm}^{-1}, 1567.45 \mathrm{~cm}^{-1}$ and $1377.59 \mathrm{~cm}^{-1}$ (Figure 5). These peaks correspond to hydroxyl, band due to scissor bending vibration of molecular water, acidic asymmetric stretch and $\mathrm{C}-\mathrm{H}$ deformations of $-\mathrm{CH}_{2}$ or $-\mathrm{CH}_{3}$ groups (lignin) in aliphatic respectively.

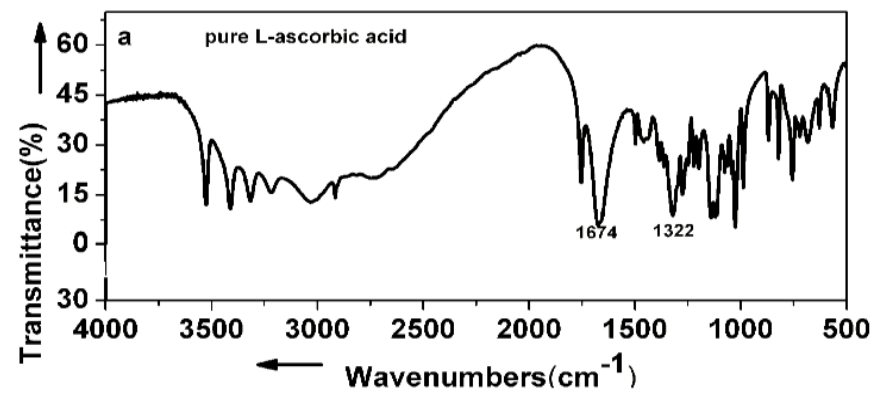

Figure 4: FTIR spectra of Pure L-Ascorbic Acid. 


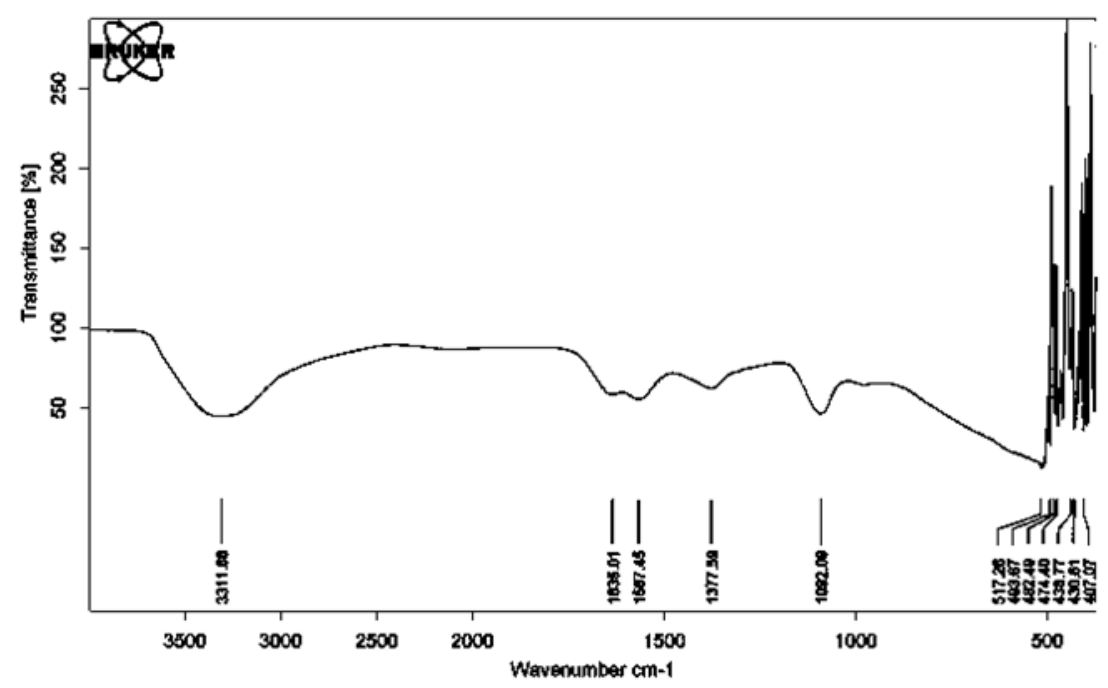

Figure 5: IR spectra of Cu NPs produced by L-Ascorbic Acid.

\subsection{X-Ray Diffraction (XRD)}

The crystal structure and average particle size of the $\mathrm{Cu}$ nanoparticles were analyzed by PANalytical, X'Pert PRO XRD system. The pattern of the prepared $\mathrm{Cu}$ nanoparticles is shown in Figure 6. It is observed that there are much broader and less intense peaks in the XRD spectrum. XRD pattern of obtained $\mathrm{Cu}$ Nanopartcles sample is made up of very small crystallites. The broadness of the peak can be used to calculate the average crystalline size of the Cu NPs using the Scherer's formula [24], $(D=0.90 \lambda / \beta \cos \theta)$, where 0.90 is a constant value known as shape factor, $\lambda$ is the wavelength of the X-rays and taken as $0.1541 \AA, \beta$ is the FWHM (full Width at half maximum) of the diffraction peaks and $\theta$ is the diffraction angle. The Experimental and Standard diffraction angles [25] of Cu NP obtained by XRD are mentioned in Table-1.

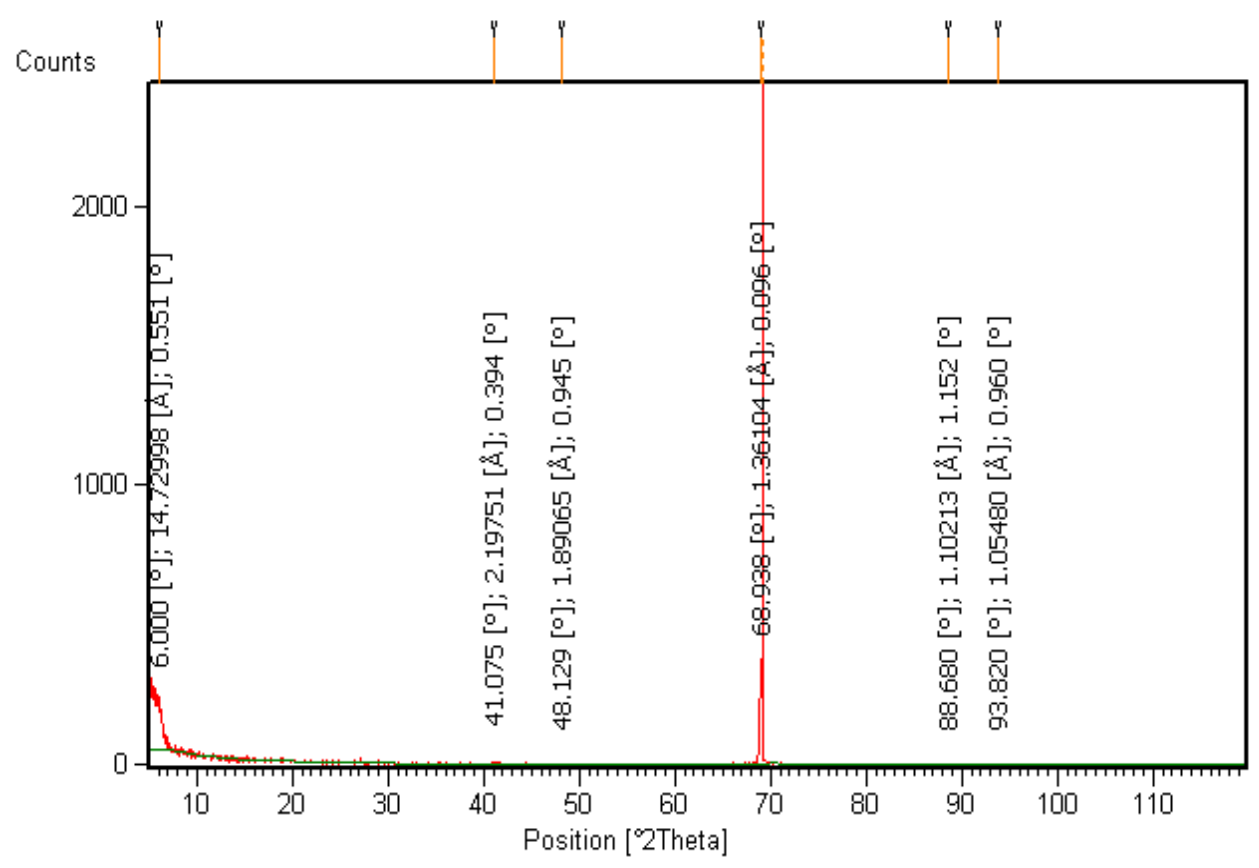

Figure 6: XRD of Copper Nanoparticles. 
Table 1. Experimental and Standard diffraction angles of Copper nanoparticles.

\begin{tabular}{lll}
\hline $\begin{array}{l}\text { Experimental } \\
\text { diff. angle }[2 \theta \\
\text { degree] }\end{array}$ & $\begin{array}{l}\text { Standard } \\
\text { in angle } \\
\text { degree] } \\
\text { JCPDS } \\
\text { 04-0836 [24,25] }\end{array}$ & $\begin{array}{c}\text { diff. Hkl (Planes) } \\
{[2 \theta \text { in }}\end{array}$ \\
\hline 41.075 & 43.297 & $(111)$ \\
\hline 48.129 & 50.433 & $(200)$ \\
\hline 69.178 & 74.130 & $(220)$ \\
\hline
\end{tabular}

The XRD pattern of the as prepared $\mathrm{Cu}$ nanoparticles is presented in Figure 6 and in good agreement with the reported XRD pattern of $\mathrm{Cu}$ nanoparticles [25]. The average crystalline size of the $\mathrm{Cu}$ nanoparticles for $0.5 \mathrm{M} \mathrm{L}$-ascorbic acid was calculated using the Scherrer's formula for the $\mathrm{Cu}$ sample is in the range of 50 $60 \mathrm{~nm}$. The values at peaks mentioned in the Table-1 are in good agreement with the spherical $\mathrm{Cu}$ phase and correspond to lattice planes of standard crystalline $\mathrm{Cu}$, respectively [26].

\section{4 STABILITY OF CU NANOPARTICLES}

The main factors that affect the use of $\mathrm{Cu}$ NP are the stability in the dispersion. Many capping agents such as Polyvinyl Pyrrolidone (PVP) and Polyethylene glycol are used to prevent agglomeration. L-Ascorbic acid was used as reducing as well as capping agent in this work to avoid contamination of other organic compounds.

The prepared $\mathrm{Cu}$ NP suspensions were placed without any further mixing or treatment for 12 weeks, no sedimentation was seen till that period. This indicates that the L-Ascorbic Acid highly stabilized the $\mathrm{Cu}$ nanoparticles due to its high capping power.

\section{CONCLUSIONS}

The L-ascorbic acid (Vitamin C) protected $\mathrm{Cu}$ NP prepared using chemical reduction of cupric chloride. The product is of uniform size 50-60 $\mathrm{nm}$ and has uniform distribution curve. It is noted that by increasing the concentration of L-ascorbic acid the concentration of nanoparticles is increased at constant concentration of cupric chloride, which is confirmed by Atomic Absorption spectrometry. The produced $\mathrm{Cu} \mathrm{NP}$ are of high stability than ever reported. The stability period is 3 months, which has been observed with no suspension or sedimentation. This is a simple, economical and green method for the synthesis of $\mathrm{Cu}$ NP with no toxic and hazardous effect.

\section{ACKNOWLEDGEMENT}

The authors express immense thanks to the Department of Chemical Engineering, Department of Physics and IEER, University of Engineering and Technology, Lahore and also thankful to Mr. Shahid Rehman Khan (SOS) of PCSIR, Lahore for providing test facilities. The financial support from the UET, Lahore-Pakistan is also gratefully acknowledged.

\section{REFERENCES}

[1] FELDHEIM, D.L., FOSS JR, C.A., Metal Nanoparticles; Synthesis, Characterization, and Applications, New York, USA, Marcel Dekker Incorporated, 2002.

[2] SIEGEL, R. W., HU, E., ROCO, M. C., Nanostructure Science and Technology: $R$ \& D Status and Trends in Nanoparticles, Nanostructured Materials, and Nano-devices, 1 ed., In: WTEC Panel Report, Kluwer Academic Press, Dordrecht, Netherland, 1999.

[3] JANA, N. R., WANG, Z. L., SAU, T. K., et al., "Seed-mediated growth method to prepare cubic Copper nanoparticles", Current Science, v. 79, n. 9, pp.1367-1370, Nov. 2000. 
[4] YEH, M. S., YANG, Y.-S., LEE, Y.-P., et al.,"Formation and Characteristics of Cu Colloids from CuO Powder by Laser Irradiation in 2-Propanol”, Journal of Physical Chemistry-B, v.103, n.33, pp.6851-7, Aug. 1999.

[5] LIU, Z., BANDO, Y. “A Novel Method for Preparing Copper Nanorods and Nanowires”, Advanced Materials, v. 15, n. 4, pp.303-305, Feb. 2003.

[6] YATSUI, K., GRIGORIU, C., KUBO, H., et al., "Synthesis of nano size powders of alumina by ablation plasma produced by intense pulsed light-ion beam”, Applied Physics Letters, v. 67, n. 9, pp.1214-1216, Aug. 1995.

[7] OLESZAKA, D., SHINGU, P.H., "Nanocrystalline metals prepared by low energy ball milling", Journal of Applied Physics, v. 79, n. 6, Mar. 1996.

[8] WANG, Y., CHEN, P., LIU, M., "Synthesis of Well-Defined Copper Nanocubes by a One-Pot Solution Process", Nanotechnology, n. 17, n.24, pp.6000-6006, 2006

[9] PILENI, M. P., "Reverse Micelles as Microreactors", The Journal of Physical Chemistry, v. 97, n.27, pp.6961-6973, Jul. 1993.

[10]KUMAR, R. V., MASTAI, Y., DIAMANT, Y., et al., "Sonochemical Synthesis of Amorphous Cu and Nanocrystalline $\mathrm{Cu}_{2} \mathrm{O}$ Embedded in a Polyaniline Matrix", Journal of Materials Chemistry, v.11, n.4, pp.1209-1213, Feb. 2001.

[11]MOLARES, MET., BUSCHMANN, V, DOBREV, D, et al., "Single-crystalline copper nanowires produced by electrochemical deposition in polymeric ion track membranes", Advanced Materials, v.13, n.1, pp.62-65, Jan. 2001.

[12]TAKAYAMA, S., LINK, G., SATO, M.., et al., Microwave and Radio Frequency Applications, In: Proceedings of the Fourth World Congress on Microwave and Radio Frequency Applications, pp.311318, Austin, Texas, USA, Nov. 2004.

[13]CHU, LY., ZHUO, Y., DONG, L., et al., "Controlled synthesis of various hollow Cu nano/microstructures via a novel reduction route", Advanced Functional Materials, v. 17, n.6, pp.933938, Feb. 2007.

[14]BALI, R., RAZAK, N., LUMB, A., et al., "The synthesis of metal nanoparticles inside live plants", In: International Conference on Nanoscience and Nanotechnology, pp.224-227, Jul. 2006.

[15]UMER, A., NAVEED, S., RAMZAN, N., et al., "Selection of a suitable method for the synthesis of Copper nanoparticles", NANO: Brief Reports and Reviews, World Scientist Publishing Company, v. 7, n. 5, Nov. 2012.

[16]BONET, F., DELMAS, V., GRUGEON, S., et al., "Synthesis of Monodisperse Au, Pt, Pd, Ru and Ir Nanoparticles in Ethylene Glycol," Nano Structured Materials, v. 11, n. 8, pp.1277-1284, Nov. 1999.

[17]MURPHY, C. J., SAN, T. K., GOLE, A. M., et al., “Anisotropic Metal Nanoparticles: Synthesis, Assembly, and Optical Applications", Journal of Physical Chemistry B, v. 109, n. 29, pp.13857-13870, Jun. 2005.

[18] SANTOS, I. PASTORIZA.,LIZ-MARZAN, L. M., "Formation and stabilization of silver nanoparticles through reduction by N, N-dimethylformamide", Langmuir, v. 15, n. 4, pp.948-951, Jan. 1999.

[19]TAN, Y. W., DAI, X. H., Li, Y. F., "Preparation of Gold, Platinum, Palladium and Silver Nanoparticles", Journal of Materials Chemistry, v. 13, n. 5, pp. 1069-1075, Mar. 2003

[20]CHOU, K. S., REN, C. Y., "Synthesis of nanosized silver particles by chemical reduction method", Materials Chemistry and Physics, v. 64, pp.241-246, May 2000.

[21]LEE, Y., CHOI, J.R., LEE, K. J., et al., "Large-scale synthesis of copper nanoparticles by chemically controlled reduction for applications of inkjet-printed electronics", Nanotechnology, v. 19, n. 41, Sep. 2008.

[22]LEOPOLD, N., LENDL, B., “A New Method for Fast Preparation of Highly Surface-Enhanced Raman Scattering (SERS) Active Silver Colloids at Room Temperature by Reduction of Silver Nitrate with Hydroxylamine Hydrochloride”, In: Journal of Physical Chemistry B, v. 107, n. 24, 5723-5727, May 2003.

[23]XIONG, JING., WANG, YE., XUE, QUNJI, et al., "Synthesis of highly stable dispersions of nanosized copper particles using L-ascorbic acid”, Green Chemistry, v. 13, n. 4, pp.900-904, Feb. 2011. 
UMER, A.; NAVEED, S.; RAMZAN, N.; RAFIQUE, M.S; IMRAM, M., revista Matéria, v. 19, n. 3, pp. 197 - $203,2014$.

[24] SCHERRER, P., "Nachrichten von der Gesellschaft der Wissenschaften zu Gittingen, MathematischPhysikalische Klasse, v. 26, n. 1, pp. 98-100, Jul. 1918.

[25] MDI (material data) Jade Software, Version-6.5, XRD data processing Card \# 04-0836.

[26]ZHOU,RUIMIN., WU, XINFENG., HAO, XUFENG, et al., "Influences of surfactants on the preparation of Copper nanoparticles by electron beam irradiation", In: Nuclear Instruments and Methods in Physics Research. Section B, Beam Interactions with Materials and Atoms, v. 266, n. 4, pp.599-603, Feb. 2008. 